\title{
Analysis of Electromagnetic Transient Characteristics of Doubly-Fed Induction Generator Under Grid Voltage Swell
}

\author{
Yonghong Deng, Zhigang Xing, and Quanzhu Zhang
}

\begin{abstract}
The electromagnetic transient characteristics (ETC) of doubly-fed induction generator (DFIG) under grid voltage dip have been extensively studied theoretically, and various control strategies have been proposed. However, the ETC of DFIG under grid voltage swell are less studied. In order to study the influence on the ETC of DFIG under grid voltage swell and the corresponding control strategy, this paper compares and analyzes the steadystate and transient components of the stator flux linkage, rotor induced voltage and rotor current of DFIG under grid voltage swell and dip. It is deduced that DFIG is less prone to rotor overcurrent under grid voltage swell so the crowbar protection circuit is not needed, and the grid voltage amplitude changes little, the rotor side inverter is less prone to overmodulation. An experimental setup and simulation model is implemented with high-voltage ride-through of $1.5 \mathrm{MW}$ doubly-fed wind Turbine. Simulation in addition to experimental results verifies the correctness and effectiveness of the theoretical analysis.
\end{abstract}

Index Terms-Doubly-fed induction generator (DFIG), electromagnetic transient characteristics (ETC), grid voltage failure, wind power generation.

\section{INTRODUCTION}

$\mathrm{I}^{\mathrm{N}}$ recent years, wind power generation has developed rapidly, and the amount of electricity delivered to the grid from wind power generation is also increasing. The high proportion of wind power grid-connected operation has brought great challenges to the safety and stability of power systems, and the impact of wind power accidents cannot be ignored [1]. The major wind power developed countries and regions in the world have adopted the grid-connected rules to regulate the grid-connected behavior of wind power, especially the fault-pass capability of wind power, including low voltage ride through (LVRT) and high voltage ride through (HVRT). Doubly-fed induction generator (DFIG) is the most widely used type of wind turbine generator because of its advantages of small capacity, low cost, and variable speed constant frequency operation. However, due to

Manuscript received June 10, 2018. This work was supported by Hebei Science and Technology Support Project $(16274603,16214408)$ and Fundamental Research Funds for the Central Universities (010202580102, 3142016022, 3142014126).

Y. Deng and Q. Zhang are with North China Institute of Science and Technology, East Yanjiao, Beijing, China (e-mail: dyhsyjdyx@163.com).

Z. Xing is with the production department of Guohua Energy Investment Co., Ltd., Hebei Branch (e-mail: xzg74@sina.com).

Digital Object Identifier 10.24295/CPSSTPEA.2018.00011 its stator windings directly connected to the grid, the excitation converter capacity is limited, causing it to be sensitive to grid disturbances, and in the event of a power grid failure, problems such as over-current, over-voltage, torque shock and pulsating output, and active and reactive power fluctuations are likely to occur, which seriously endanger the unit's operation safety and affect the output power quality.

For the low-voltage ride-through problem of the grid-connected operation of doubly-fed wind turbines, there has been a lot of theoretical research and engineering practice. These LVRT schemes can be summarized as hardware-based and control-based algorithms. Based on the hardware scheme, the topological structure of the doubly-fed wind power converter is implemented through additional hardware devices to improve the LVRT capability of the wind turbine [2], [3]. Based on the control algorithm, the control strategy is optimized based on the operating characteristics of the DFIG unit. Documents [4] and [5] comprehensively discuss several commonly used and improved control strategies for solving the problem of low-voltage ride-through of doubly-fed wind turbines. Aiming at the characteristics of DFIG, a large number of literatures have done indepth research on the transient characteristics of DFIG during low-breakage faults, and given a variety of solutions. The literature [6]-[8] studied the electromagnetic transient characteristics of DFIG and the short-circuit current under LVRT control when the voltage of the power grid falls, and provided the theoretical basis for the relevant LVRT strategy. According to the transient characteristics of DFIG when voltage drops, the literature [9] is based on the idea of "demagnetization", by timely and accurately injecting the transient compensation amount on the rotor side, the controllability in the LVRT process of the unit is effectively improved, and the LVRT performance of the double-fed unit is improved. Literature [10] and literature [11] proceeded from the direction of speeding up the decay of the stator flux transients and proposed the virtual inductance demagnetization control and virtual resistance control respectively. Corresponding to the voltage drop, the voltage swell occurs when the grid voltage recovers or the grid reactive power excess time. If the unit does not consider the over-voltage protection design at this time and does not have the HVRT control capability, it must be disconnected from the power grid to generate a large-scale off-grid phenomenon of the wind turbine. At present, there are few researches on transient characteristics and related countermeasures of DFIG when the voltage of power grid is suddenly increased. Literature [12], [13] proposed an improved control 
strategy based on variable damping and virtual impedance to improve the high-voltage ride-through performance of the unit, but the article proposes a control strategy only from the theoretical analysis point of view. It does not do a detailed analysis of the changes in the electromagnetic quantities of the DFIG when the grid voltage swells, and does not consider the effect of the actual surge amplitude of the grid voltage. Considering the voltage drop and swell of the power grid, the transient processes of the stator flux linkage, rotor induced electromotive force and rotor current of the DFIG are similar. Based on the theoretical calculation, experiment and simulation verification, this paper analyzes the change process and influencing factors of DFIG electromagnetic flux when the power grid falls and swells separately, and compares the similarities and differences between the two faults. It provides theoretical support for the study of the HVRT control strategy of the double-fed unit and defines the key to the HVRT control of the DFIG unit.

\section{The Mathematical Model of DFIG}

In the stator stationary frame, the vector form of the doubly-fed motor voltage equation and the flux linkage equation are

$$
\begin{aligned}
& \left\{\begin{array}{l}
\boldsymbol{u}_{s}=R_{s} \boldsymbol{i}_{s}+\frac{d}{d t} \boldsymbol{\psi}_{s} \\
\boldsymbol{u}_{r}=R_{r} \boldsymbol{i}_{r}+\frac{d}{d t} \boldsymbol{\psi}_{r}-\mathrm{j} \omega_{r} \boldsymbol{\psi}_{r}
\end{array}\right. \\
& \left\{\begin{array}{l}
\boldsymbol{\psi}_{s}=L_{s} \boldsymbol{i}_{s}+L_{m} \boldsymbol{i}_{r} \\
\boldsymbol{\psi}_{r}=L_{r} \boldsymbol{i}_{r}+L_{m} \boldsymbol{i}_{s}
\end{array}\right.
\end{aligned}
$$

(1) is the voltage equation, and (2) is the flux linkage equation. Where $\boldsymbol{u}_{s}$ and $\boldsymbol{u}_{r}$ are stator and rotor voltages, $R_{s}$ and $R_{r}$ are stator and rotor resistances, $\boldsymbol{i}_{s}$ and $\boldsymbol{i}_{r}$ are stator and rotor currents, respectively; $\psi_{s}$ and $\psi_{r}$ are fixed and rotor flux chains, $\omega_{r}$ is the rotor angular velocity, and $L_{s}, L_{r}$ and $L_{m}$ are stator inductance, rotor inductance and mutual inductance, respectively.

According to the voltage equation of (1), the equivalent circuit of DFIG shown in Fig. 1 can be obtained. $L_{l s}$ and $L_{l r}$ in Fig. 1 are stator leakage inductance and rotor leakage inductance, respectively.

\section{Stator Flux Transient Analysis of Grid Voltage Swell and Drop Fault}

Assume that the system is operating stably before $t_{0}$, the stator voltage at this time can be expressed as

$$
\boldsymbol{u}_{s}=U e^{j \omega_{1} t}\left(t<t_{0}\right)
$$

where $U$ is the stator voltage amplitude and $\omega_{1}$ is the stator synchronous angular velocity.

If the grid voltage occurs symmetrical fault at $t_{0}$, set the grid voltage amplitude change degree $\mathrm{p}$, and when $p<0$ system voltage drop fault occurs, the drop depth is $|\mathrm{p}|$; when $p>0$, a voltage surge fault occurs and the magnitude of the

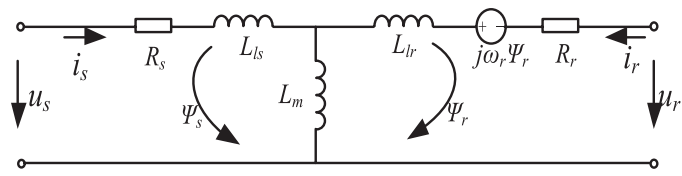

Fig. 1. Equivalent circuit of DFIG.

swell is $|p|$. In this process, the stator voltage can be expressed as

$$
\boldsymbol{u}_{s}=(1+p) U e^{j \omega_{1} t}\left(t \geq t_{0}\right)
$$

The corresponding stator steady state flux chain expression is

$$
\boldsymbol{\psi}_{s}= \begin{cases}\frac{U}{j \omega_{1}} e^{j \omega_{1} t} & t<t_{0} \\ \frac{(1+p) U}{j \omega_{1}} e^{j \omega_{1} t} & t \geq t_{0}\end{cases}
$$

In the course of grid voltage faults, the stator flux linkage gradually transitions from one steady state to another because the flux cannot mutate. In order to facilitate the analysis of the transient process of the stator flux linkage when the grid voltage amplitude changes, it is assumed that the rotor is open, i.e. the rotor current is zero. Then substituting the stator flux equation in (2) into the stator voltage equation in (1) gives the stator flux differential equation

$$
\frac{d}{d t} \boldsymbol{\psi}_{s}=\boldsymbol{u}_{s}-\frac{R_{s}}{L_{s}} \boldsymbol{\psi}_{s}
$$

Solving this differential equation yields

$$
\boldsymbol{\psi}_{s}=\frac{(1+p) U}{j \omega_{1}} e^{j \omega_{1} t}+\boldsymbol{\psi}_{n 0} e^{-t / \tau_{s}}
$$

where, $\boldsymbol{\Psi}_{n 0}$ is a constant related to the fault condition, $\tau_{s}=\frac{R_{S}}{L_{s}}$.

It is analyzed that the solution of the flux differential equation is composed of homogeneous solution and nonhomogeneous solution. Where, the non-homogeneous solution is the steady-state component of the flux linkage $\boldsymbol{\Psi}_{s n}$, its amplitude is related to the stator voltage, and its frequency is the synchronous angular frequency; the homogeneous solution is the transient decay component of the flux linkage $\boldsymbol{\Psi}_{s n}$, which reflects the continuity of the flux linkage change and is an exponentially decaying DC value.

Since the instantaneous value of the flux linkage is the same before and after the grid voltage fault, there are

$$
\boldsymbol{\psi}_{s f}\left(t_{0}^{-}\right)=\boldsymbol{\psi}_{s f}\left(t_{0}^{+}\right)+\boldsymbol{\psi}_{s n}\left(t_{0}^{+}\right)
$$

Assuming that the grid voltage fault occurs at time $t_{0}=0$, the corresponding expressions in (5) and (6) are substituted into (8). After the fault occurs, the complete expression of 


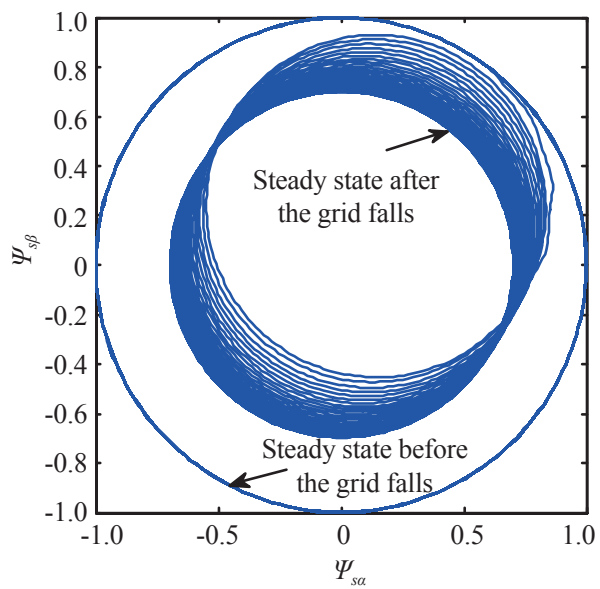

(a) grid voltage dip

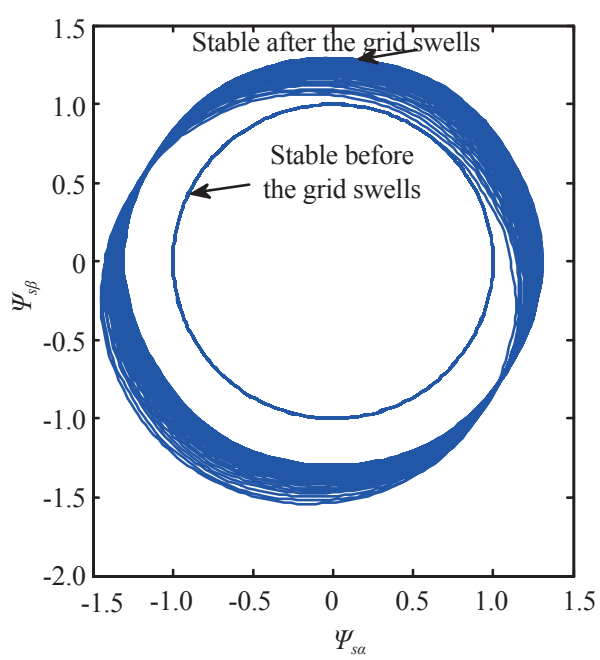

(b) grid voltage swell

Fig. 2. Stator flux waveforms in $\alpha \beta$ frames during grid voltage fault.

the stator flux linkage is

$$
\boldsymbol{\psi}_{s}=\boldsymbol{\psi}_{s f}+\boldsymbol{\psi}_{s n}=\frac{(1+p) U}{j \omega_{1}} e^{j \omega_{1} t}-\frac{p U}{j \omega_{1}} e^{-\frac{t}{\tau_{s}}}
$$

From (9), the change process of the stator flux linkage in the $\alpha \beta$ coordinate system is shown in Fig. 2 after the grid voltage has dropped and swelled. The steady state of the stator flux is a circle with a constant amplitude, a fixed center and a rotation at the synchronous angular frequency. When a threephase grid voltage drop or swell failure occurs, the amplitude of the flux linkage cannot be abrupt, and under the action of the DC transient component, it gradually shifts to a new steady state in a way that the center is shifted, and steady-state pre-fault constitute concentric circles.

\section{Rotor Induced Voltage of Grid Voltage Swell AND DROP FAULT}

After the grid voltage fails, the two components of the stator flux will each generate an induced electromotive force in the rotor, and thus a transient process will also occur in the rotor induced electromotive force. And because the output voltage controllable range of voltage source type inverter is limited, so need to consider the rotor end voltage when the voltage fault of the power grid.

According to the DFIG mathematical model, from (2) can get

$$
\boldsymbol{\psi}_{r}=L_{m} \boldsymbol{\psi}_{s} / L_{s}-\sigma L_{r} \boldsymbol{i}_{r}
$$

where: $\sigma=1-L_{m}^{2} /\left(L_{s} L_{r}\right)$.

Substituting (10) into (1), the expression of the rotor voltage can be obtained as

$$
\boldsymbol{u}_{r}=L_{m}\left(d / d t-j \omega_{r}\right) \boldsymbol{\psi}_{s} / L_{s}+\left[R_{r}+\sigma L_{r}\left(d / d t-j \omega_{r}\right)\right] \boldsymbol{i}_{r}
$$

The first term in (11) is the induced electromotive force generated by the stator flux on the rotor loop, denoted by $\boldsymbol{u}_{r 0}$, which is the open circuit voltage of the rotor; and the second term is the impedance drop of the rotor loop.

The induced electromotive force generated on the rotor loop by the steady-state and transient components of the stator flux is denoted by $\boldsymbol{e}_{r f}$ and $\boldsymbol{e}_{r m}$, respectively, and its relationship with the open-circuit voltage of the rotor can be expressed as

$$
\boldsymbol{u}_{r 0}=\boldsymbol{e}_{r f}+\boldsymbol{e}_{r n}
$$

Calculated by (9) and (11) are available

$$
\left\{\begin{aligned}
\boldsymbol{e}_{r f} & =L_{m} / L_{s}(1+p) U s e^{j \omega_{1} t} \\
\boldsymbol{e}_{r n} & =\left(L_{m} / L_{s}\right)\left(p U / j \omega_{1}\right) e^{-t / \tau_{s}}\left(1 / \tau_{s}+j \omega_{r}\right) \\
& =-\left(L_{m} / L_{s}\right)\left(1 / \tau_{s}+j \omega_{r}\right) \boldsymbol{\psi}_{s n}
\end{aligned}\right.
$$

where, $s=\left(\omega_{1}-\omega_{r}\right) / \omega_{1}$ is the slip ratio.

Ignoring the smaller $1 / \tau_{s}$ terms, there are

$$
\boldsymbol{e}_{r n} \approx-j \omega_{r}\left(L_{m} / L_{s}\right) \boldsymbol{\psi}_{s n}
$$

Therefore, the open circuit voltage of the rotor is

$$
\boldsymbol{u}_{r 0}=L_{m} / L_{s}(1+p) U s e^{j \omega_{1} t}-j \omega_{r}\left(L_{m} / L_{s}\right) \boldsymbol{\psi}_{s n}
$$

The conversion of (15) to the rotor coordinate system can be expressed as

$$
\boldsymbol{u}_{r o}^{r}=L_{m} / L_{s} U\left[(1+p) s e^{j \omega_{s} t}+(1-s) p e^{-j \omega_{r} t} e^{-t / \tau_{s}}\right]
$$

From (16), it can be seen that after the grid fault, the steadystate amplitude of the open-circuit voltage of the rotor is $1+p$ times that before the grid fault.

The transient amplitudes of the open-circuit voltage of the rotor are the same when the voltage drop fault and the swell fault of the power grid occur, and the phases are 180 degrees apart.

Simulation of the same doubly-fed generator in the open rotor case, the running slip is -0.2 , when the stator voltage drop 


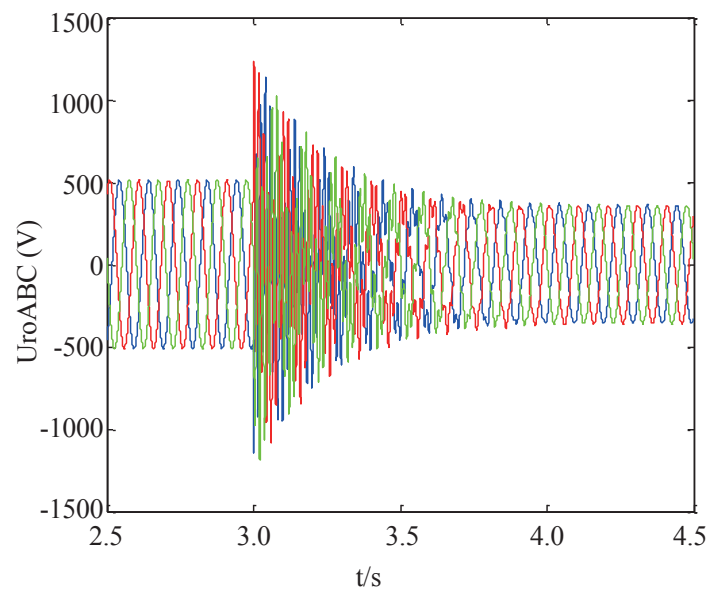

(a) grid voltage dip

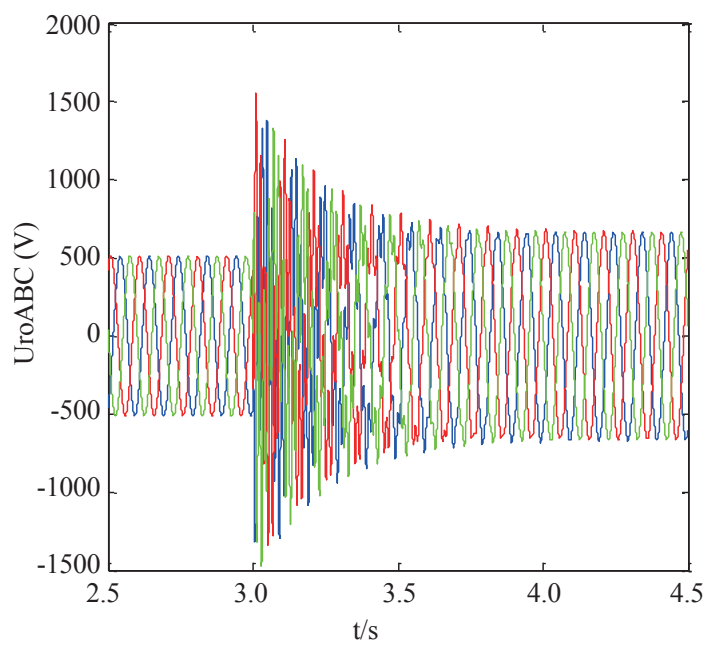

(b) grid voltage swell

Fig. 3. Rotor three-phase open circuit voltage in grid fault.

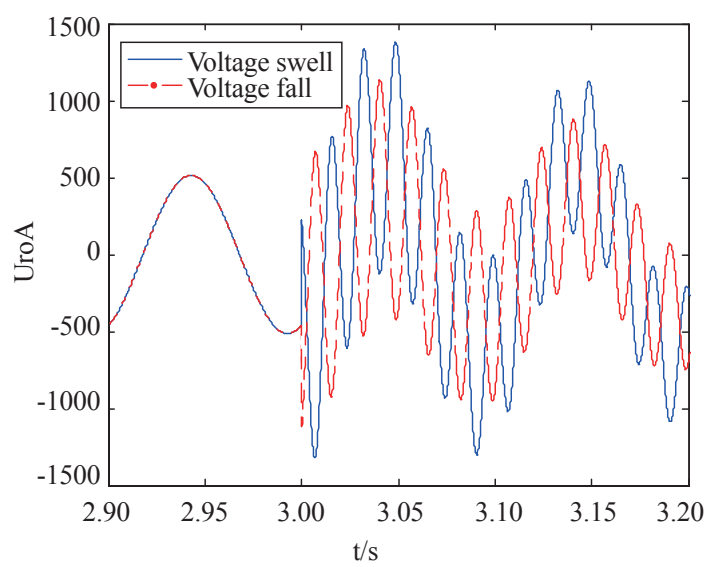

Fig. 4. A phase voltage of rotor in power grid failure.

or swell $30 \%$, the rotor of the motor induced transient changes in the electromotive force. As shown in Fig. 3, the three-phase open circuit voltage of the rotor when the stator voltage drops and swells. It can be seen that the steady-state amplitude of the open-circuit voltage of the rotor is $1+p$ times before the fault, and the steady-state frequency is $10 \mathrm{~Hz}$. In Fig. 4, taking the a-phase of the opencircuit voltage of the rotor as an example, the transient change of the open-circuit voltage of the rotor when the stator voltage is dropped or swelled separately at $3 \mathrm{~s}$ is compared. As can be seen from the figure, the transient amplitudes of the open-circuit voltages of the rotors are equal in both cases and the phases are 180 degrees out of phase. In the case where the slip is -0.2 , the frequency of transient components in the rotor coordinate system is $60 \mathrm{~Hz}$.

\section{Rotor Current of Grid Voltage Swell and Drop FAULT}

When the double-fed unit is operating normally, the influence of rotor current should be considered. The expression of the rotor voltage in (11) in the stator coordinate system is transformed into a synchronous rotating coordinate system, finally get

$$
\sigma L_{r} \frac{d \boldsymbol{i}_{r, d q}}{d t}+\left(R_{r}+j \omega_{s} \sigma L_{r}\right) \boldsymbol{i}_{r, d q}=\boldsymbol{u}_{r, d q}-\boldsymbol{u}_{r 0, d q}
$$

where, the subscript $d q$ in $\boldsymbol{i}_{r, d q}, \boldsymbol{u}_{r, d q}, \boldsymbol{u}_{r 0, d q}$ represents the value of this vector in $d q$ synchronous rotating coordinate system, $\boldsymbol{u}_{r 0, d q}=L_{m} / L_{s} U\left[(1+p) s+(1-s) p e^{-j \omega_{1} t} e^{-t / \tau s}\right] . \boldsymbol{u}_{r, d q}$ is the AC output voltage of the rotor side converter, which reflects the influence of the control performance of the rotor side converter on the rotor current. From (17), it can be seen that when the grid fault occurs, the rotor current change is determined by both the stator flux linkage and the rotor-side converter, and the interaction relationship is related to the generator electromagnetic parameters and the rotation speed. The rotor-side converter changes the AC-side output voltage according to the active and reactive control strategy to track the set rotor current, and the rotor current can be approximated as a reference value. After the grid fails, it is assumed that the capacity of the converter is sufficiently large and the rotor crowbar protection does not act. The size of the rotor voltage is affected by the rotor-side converter control system. The rotor-side converter control of DFIG often adopts vector control mode of stator flux orientation, and the decoupled control of active and reactive power is achieved by means of feedforward compensation of coupling terms. Fig. 5 shows the control block diagram of the rotor-side converter. $i_{r d}^{*}$ and $i_{r q}^{*}$ are the reference values of the $\mathrm{d}$, q-axis current components of the rotor, respectively, and are determined by the reference values of the active and reactive power. $u_{r d}{ }^{*}$ and $u_{r q}{ }^{*}$ are the rotor voltage reference values needed to track the rotor current.

From Fig. 5, the control equation is

$$
\left\{\begin{array}{l}
u_{r d}^{*}=k_{p} \Delta i_{r d}+k_{i} \int \Delta i_{r d} d t-\omega_{s} \sigma L_{r} i_{r q} \\
u_{r q}^{*}=k_{p} \Delta i_{r q}+k_{i} \int \Delta i_{r q} d t+\omega_{s} \sigma L_{r} i_{r d}
\end{array}\right.
$$

where, $\Delta i_{r d}=i_{r d}^{*}-i_{r d}, \Delta i_{r q}=i_{r q}^{*}-i_{r q}, k_{p}$ and $k_{i}$ are the ratios and 


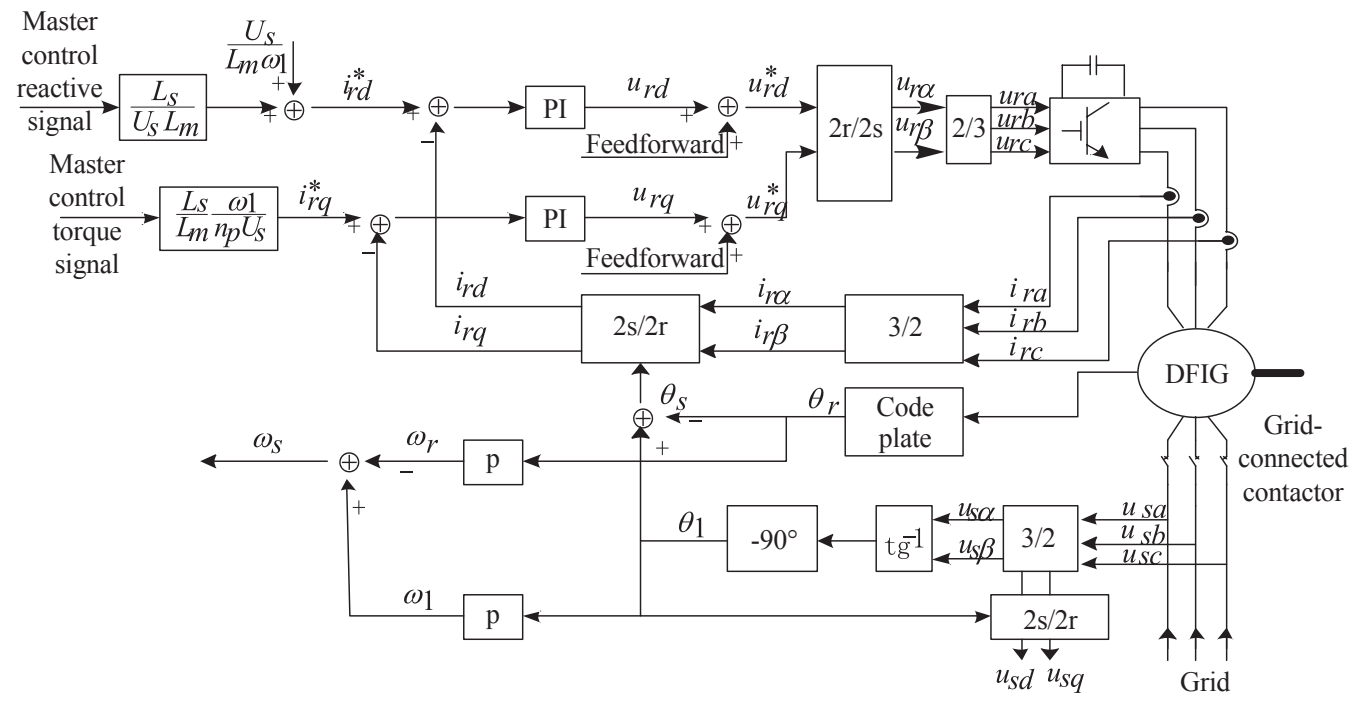

Fig. 5. Stator flux oriented VC control diagram of DFIG.

integral coefficients of the current loop controller, respectively.

Assuming that the closed-loop bandwidth of the current control loop is large enough, the voltage on the AC side of the converter can track the reference value without any error, and the switching transients are ignored, then the rotor voltage space vector in the synchronous rotating coordinate system when the power grid fails can be written as

$$
\boldsymbol{u}_{r, d q}=k_{p}+k_{i} \int\left(\boldsymbol{i}_{r, d q}^{*}-\boldsymbol{i}_{r, d q}\right)+j \omega_{s} \sigma L_{r} \boldsymbol{i}_{r, d q}
$$

Combining (17) and (19), considering the influence of stator flux and converter control system on rotor current, the rotor current dynamic equation after grid short circuit can be obtained

$$
\frac{d^{2} \boldsymbol{i}_{r, \mathrm{dq}}}{d t^{2}}+\mu \frac{d \boldsymbol{i}_{r, d q}}{d t}+v \boldsymbol{i}_{r, d q}=v \boldsymbol{i}_{r, d q}^{*}-\lambda \boldsymbol{e}_{r n, d q}
$$

where, $\mu=\left(R_{r}+k_{p}\right) / \sigma L_{r} ; v=k_{i} / \sigma L_{r} ; \lambda=\left(j \omega_{1}+1 / \tau_{s}\right) / \sigma L_{r} ; \boldsymbol{e}_{r n, d q}=$ $L_{m} / L_{s} U(1-s) p e^{-j \omega_{1} t} e^{-t / \tau_{s}}$.

According to the principle of solving the second-order constant-coefficient differential equation and solving the differential equation in (12), the rotor current under the combined action of the rotor induced electromotive force and the rotor-side converter control can be obtained:

$$
\boldsymbol{i}_{r, \mathrm{dq}}=\boldsymbol{i}_{r f, \mathrm{dq}}+\boldsymbol{i}_{r n 1, \mathrm{dq}}+\boldsymbol{i}_{r n 2, \mathrm{dq}}
$$

$\boldsymbol{i}_{r n 1 \mathrm{dq}}$ is the special solution of the differential equation at the input $v i_{r, d q}^{*}$, that is the forced component of the rotor current and is the response of the rotor current to the control quantity of the rotor-side converter. According to the previous assumption that the closed-loop bandwidth of the current control loop is large enough, there are

$$
\boldsymbol{i}_{r n 1, \mathrm{dq}}=\boldsymbol{i}_{r, d q}^{*}
$$

$\boldsymbol{i}_{r n 2, \mathrm{dq}}$ is the special solution of the differential equation at the input $-\lambda \boldsymbol{e}_{r n, d q}$ and is the response of the rotor current to the transient dc back-EMF component $\boldsymbol{e}_{r n, d q}$

$\boldsymbol{i}_{r n 2, \mathrm{dq}}=-\frac{\lambda \boldsymbol{e}_{r n, d q}}{\tau_{s}^{\prime 2}-\mu \tau_{s}^{\prime}+\lambda}=-\frac{\lambda L_{m} U(1-s) p e^{-\tau_{s}^{\prime} t}}{L_{s}\left(\tau_{s}^{\prime 2}-\mu \tau_{s}^{\prime}+\lambda\right)}$

where, $\tau_{s}^{\prime}=j \omega_{1}+1 / \tau_{s}$.

$\boldsymbol{i}_{r f \mathrm{dq}}$ is the general solution of the second-order differential equation, which is the natural component of the rotor current and is related to the current $\boldsymbol{i}_{r 0, \mathrm{dq}}$ when the rotor is operating normally

$$
\boldsymbol{i}_{r f, \mathrm{dq}}=\frac{r_{1} e^{r_{2} t}-r_{2} e^{r_{1} t}}{r_{1}-r_{2}} \boldsymbol{i}_{r 0, d q}
$$

where, $r_{1}$ and $r_{2}$ are the characteristic roots of differential equations.

$$
r_{1,2}=\frac{-\mu \pm \sqrt{\mu^{2}-4 v}}{2}
$$

From the above derivation we can see that under the controllable conditions of the rotor-side converter, the rotor current contains the periodic component and the transient dc component. Among them: The steady-state component $\boldsymbol{i}_{r n 1, \mathrm{dq}}$ is the periodic component of the rotor current, the value of which is determined by the output control strategy of the rotor-side converter; the transient component $\boldsymbol{i}_{r f \mathrm{dq}}$ is the natural component of the rotor current and is only related to the parameters of the generator and the converter; the transient dc component $\boldsymbol{i}_{r n 2, \mathrm{dq}}$ is generated by the rotor's transient dc back-EMF, and its magnitude is related to the voltage drop and speed of the machine terminal, which reflects the influence of the voltage amplitude change on the rotor current when the grid voltage fails. Of the three components of the rotor current, only $\boldsymbol{i}_{r n 2, \mathrm{dq}}$ is related to the magnitude $\mathrm{p}$ of the grid voltage change. It can be seen from the expression of $\boldsymbol{i}_{r m 2, \mathrm{dq}}$ that if other control conditions are not changed, when the grid voltage drops or swells by the same 


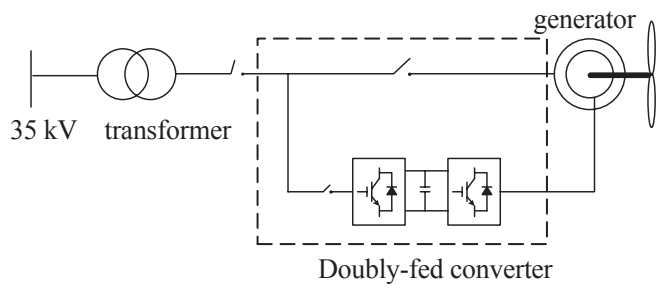

Fig. 6. Experiment and simulation structure diagram of DFIG.

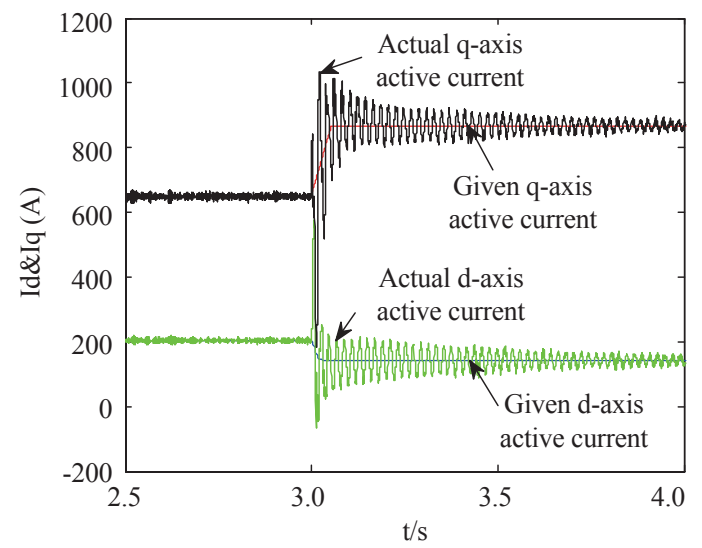

(a) grid voltage dip

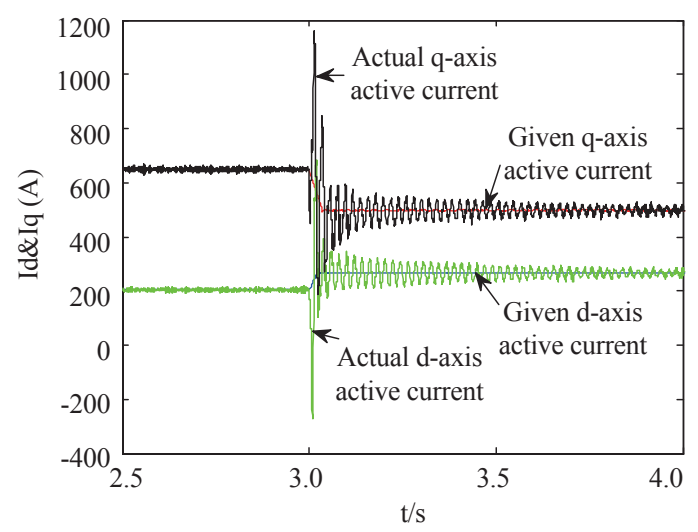

(b) grid voltage swell

Fig. 7. Rotor current in dq frame with $30 \%$ change in grid voltage amplitude.

magnitude, the amplitude of the rotor current changes caused by the transient dc component of the stator flux is the same, but the phase difference is 180 degrees. In addition, (23) shows that, considering the influence of the rotor-side converter, the magnitude of the transient DC component of the rotor current is also closely related to the control parameters of the rotor-side converter.

The 1.5 MW double-fed converter experiment and simulation system is shown in Fig. 6. The parameters of the generator used are: stator rated voltage is $690 \mathrm{~V}$; rotor open circuit voltage is $1900 \mathrm{~V}$; stator resistance is $0.0154 \Omega$; rotor resistance is $0.0033 \Omega$; the stator leakage inductance is $0.034 \Omega$; the rotor leakage inductance is $0.0297 \Omega$; the magnetizing inductance is $1.2 \Omega$; the rotor speed is $1800 \mathrm{rpm}$; the proportional constant of the rotor side current transformer PI current controller is 5 , and the integral constant is 0.05 .

As shown in Fig. 7, when the grid voltage drops by $30 \%$

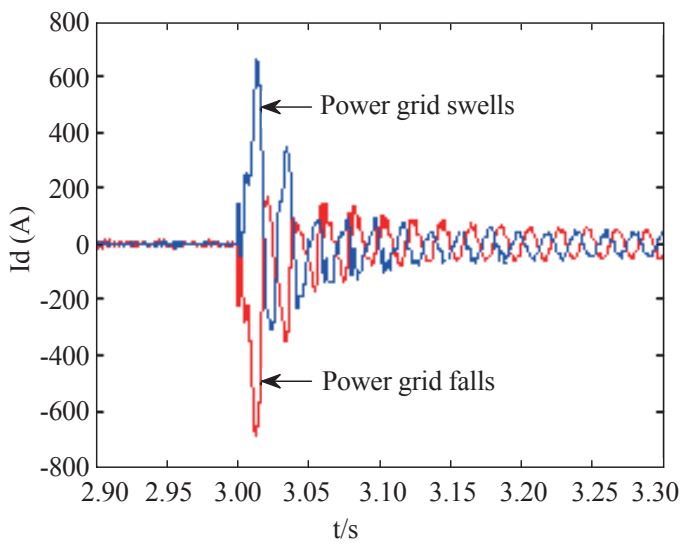

(a) Iq

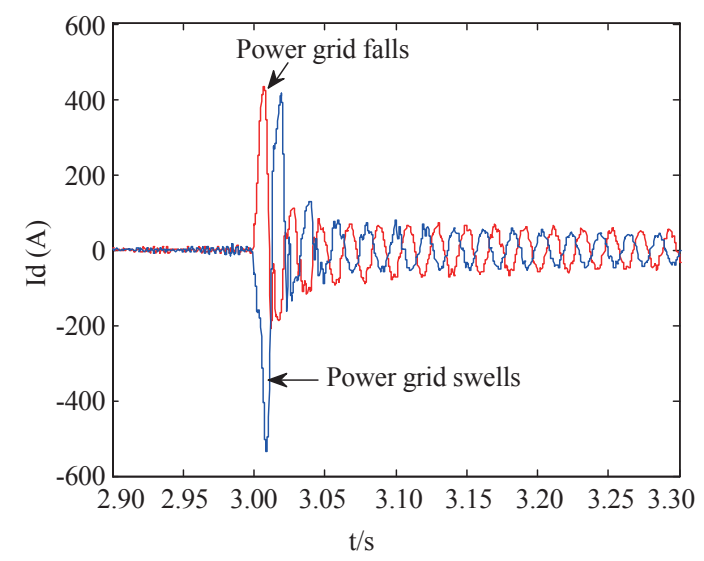

(b) Id

Fig. 8. Rotor current in dq frame of power grid swell and drop.

and swells by $30 \%$, respectively, the rotor dq axis current is given and actual value based on the synchronous rotation coordinate system of the stator flux linkage orientation. When the power grid fails, the rotor dq-axis current superimposes a transient current component whose main frequency is $60 \mathrm{~Hz}$ and whose amplitude gradually decays.

Fig. 8 shows the comparison of the transient current component of the dq axis of the rotor after the same amplitude $(30 \%)$ of drop and swell failure occurred at the same time, confirming the theoretical analysis results, that is, the grid voltage fault affects the transient decay component of the rotor current $\boldsymbol{i}_{r z 2, \mathrm{dq} q}$ The rotor transient current amplitude caused by the two faults is equal and the phase difference is 180 degrees. However, since the rotor current is also superimposed with the natural component $\boldsymbol{i}_{r \mathrm{fd}, \mathrm{d}}$, which is the amount related to the current $\boldsymbol{i}_{r \mathrm{r}, \mathrm{dq}}$ when the rotor is in normal operation, thus, the amplitude of the rotor transient current under the two grid faults is not exactly equal, and the phase is not exactly 180 degrees out of phase.

\section{EXPERIMENT VERIFICATION}

Fig.9 shows high and low voltage ride through fault results of 1.5 MW doubly-fed converter. Fig.9(a) shows the experimental waveforms for DFIG current and voltage when 


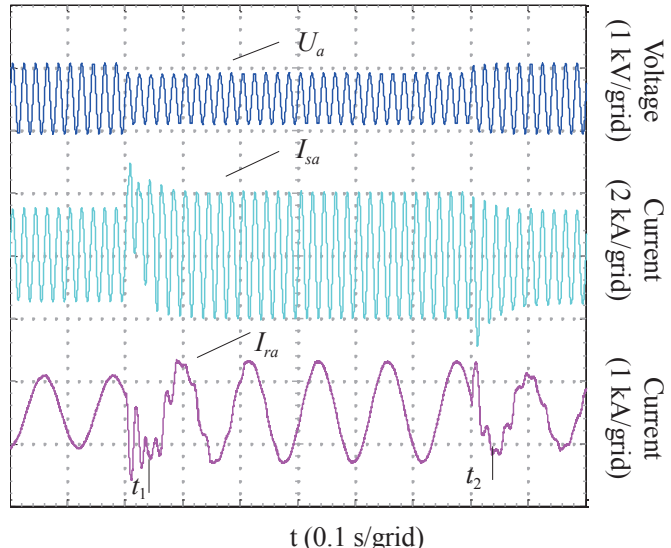

(a) Experimental waveforms for DFIG current and voltage when the grid voltage drop to $70 \%$.

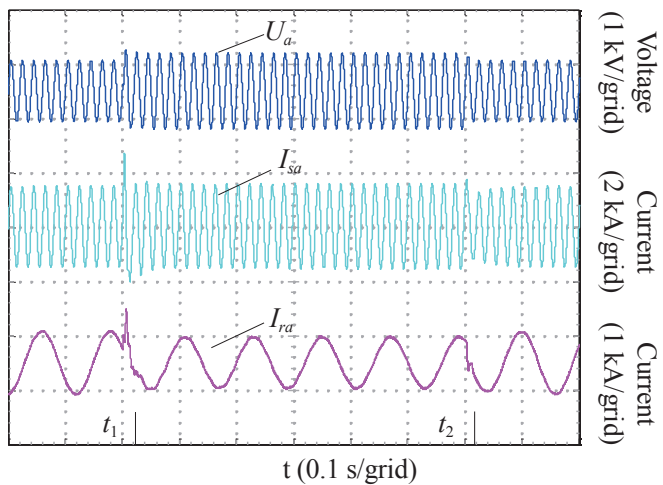

(b) Experimental waveforms for DFIG current and voltage when the grid voltage swelling to $130 \%$.

Fig. 9. High and low voltage ride through fault results of $1.5 \mathrm{MW}$ doubly-fed converter.

the grid voltage drop to $70 \%$, and (b) shows the experimental waveforms for DFIG current and voltage when the grid voltage swelling to $130 \%$. Where $U_{a}$ is A phase grid voltage, $I_{s a}$ is A phase stator current, $I_{r a}$ is A phase rotor current, $t_{1}$ is the grid fault start time, $t_{2}$ is the grid voltage recovery moment. Fig.9 show that the experimental results are consistent with the theoretical analysis when the grid voltage is reduced by $30 \%$ or increased by $30 \%$.

\section{CONCLUSION}

By comparing the generator's electromagnetic transients during grid voltage dips and swell faults, it can be concluded that:

1) After two kinds of faults, the steady-state amplitude of the stator flux linkage、 rotor open circuit voltage and rotor current is related to the magnitude of the voltage after the fault. Among them, the steady-state amplitude after the stator flux linkage and the open circuit voltage fault is $(1+p)$ times before the fault.

2) The amplitudes of the transient attenuation components of the stator flux linkage, rotor open circuit voltage, and rotor current under the two faults are equal, and the attenuation speeds are the same and the phases are 180 degrees out of phase.

3) The most severe situation of the grid voltage drop is that the voltage drops to 0 , that is, $\mathrm{p}=-100 \%$. And the most severe situation of the grid voltage swell is $p=30 \%$, so the grid voltage swell without causing a particularly strong electromagnetic transient state process. From the conclusion in 2), it can be seen that when high-voltage ride through is performed on a unit that already has low-voltage ride through capability, only the influence of the phase of the transient component needs to be considered in the low voltage ride-through electromagnetic transient suppression strategy.

4) Since the steady-state amplitude of the open-circuit voltage of the rotor is approximately $s$ (slip rate) times the magnitude of the stator voltage, the $s$ of a doubly-fed machine is generally between -0.25 and 0.25 , and the amplitude of the sudden rise $\mathrm{p}$ is up to $30 \%$. From (16), $\boldsymbol{u}_{r o \text { max }}^{r}=0.55 L_{m} / L_{s} U$ is known, so the rotor side converter is less prone to overmodulation.

This paper only compares the changes of the electromagnetic quantity of the generator when the grid voltage drops and swells, and does not consider the control of the grid-side converter. Since the grid-side converter is directly connected to the grid, when the grid voltage suddenly rises to 1.3 times the high voltage, it is necessary to consider withstand voltage capability of the components of the grid-side converter, especially the power unit. Moreover, it can be known from the vector control theory that the high voltage on the AC side causes overmodulation of the converter, resulting in uncontrollable current. In view of the possible over-modulation of the grid-side converter, the method of dynamically adjusting the DC bus voltage reference and controlling the network side to absorb reactive power to reduce the voltage of the $\mathrm{AC}$ side terminal can be improved.

\section{REFERENCES}

[1] H. Zhang, "Impact of large-scale wind power integration on power system security and stability," North China Electric Power University, Beijing, China, 2008.

[2] J. Lopez, E. Gubia, and E. Olea et al., "Ride through of wind turbines with doubly fed induction generator under symmetrical voltage dips," IEEE Transactions on Industrial Electronics, vol. 56, no. 10, pp. 42464254, 2009 .

[3] P. S. Flannery and G. Venkataramanan, "Unbalanced voltage sag ridethrough of a doubly fed Induction generator wind turbine with series grid-side converter," IEEE Transactions on Industry Applications, vol. 45 , no. 5, pp. 1879-1887, 2009.

[4] Y. He and J. Hu, "Several hot issues in gridconnected operation of doubly-fed asynchronous wind turbines," Proceedings of the CSEE, vol. 32, no. 27, pp. 1-15, 2012.

[5] R. Cardenas, R. Pena, and S. Alepuz et al., "Overview of control systems for the operation of DFIGs in wind energy applications," IEEE Transactions on Industrial Electronics, vol. 60, no. 7, pp. 2776-2798, 2013.

[6] X. Xiong and J. Ouyang, "Analysis and calculation of rotor current of doubly fed induction generator under short circuit of power network," Proceedings of the CSEE, vol. 32, no. 28, pp. 114-121, 2012.

[7] S. Yang, D. Sun, and L. Chen et al., "Research on electromagnetic transient process of doubly-fed wind generator based on analytic 
method in fault of power grid," Proceeding of the CSEE, vol. 33, no. 1, pp. 13-20, 2013.

[8] J. Yin, T. Bi, and A. Xue et al., "Short-circuit current characteristics and fault analysis methods for doubly-fed wind turbines with low voltage ride-through control," Journal of Electric Engineering, vol. 30, no. 28, pp. 116-125, 2015.

[9] S. Yang, L. Chen, D. Sun, and X. Zhang, "Research on low voltage ride through control strategy based on transient compensation algorithm," Power Electronics, vol. 45, no. 5, pp. 4-7, 2014.

[10] S. Yang, Y. Chen, and T. Zhou et al., "Virtual inductor transient self-excitation control for doubly-fed wind turbine in low voltage ride through process," Automation of Electric Power Systems, vol. 39, no. 4, pp. 12-18, 2015.

[11] P. Cheng, W. Nian, and Z. Zhu, "Virtual resistance control technology of double-fed motor in symmetry failure of power grid," Journal of Motors and Control, vol.18, no. 6, pp. 1-8, 2014.

[12] Z. Xie, X. Zhang, and H. Song et al., "Variable damping control strategy for doubly-fed wind generator under sudden jump of power grid," Power System Automation, vol. 36, no. 3, pp. 39-46, 2012.

[13] Z. Xie, X. Zhang, and Sh. Yang et al., "High-voltage ride-through control strategy for doubly-fed wind generator based on virtual impedance," Proceedings of the CSEE, vol. 32, no. 27, pp. 16-23, 2012.

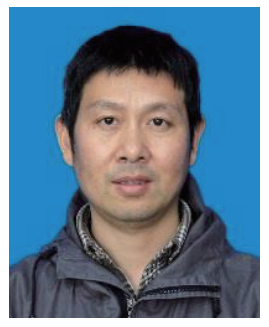

Yonghong Deng received his M.S. degree in the School of Electrical Engineering, Beijing Jiaotong University, Beijing, China in 2005, and is a Ph.D. student in the College of Geophysics and information Engineering, China University of Petroleum(Beijing), Beijing, China. He worked in the School of North China Institute of Science and Technology, East Yanjiao, Beijing, China, where he is currently a associate professor. His main research interests power electronics and electric drive.

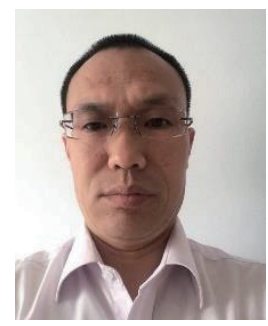

Zhigang Xing, male, born in 1974, Zhangjiakou City, Hebei Province, college graduate, engineer, deputy manager of production department of Guohua Energy Investment Co., Ltd. Hebei Branch.

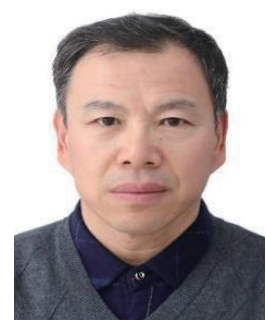

Quanzhu Zhang, male, born in 1965, is a post-doctoral student in Wulanchabu, Inner Mongolia. Now he is the deputy director of Electronic Information Engineering Department of North China Institute of Science and Technology. The main research directions are power electronics and power drag, computer measurement and control technology. 